This item was submitted to Loughborough's Research Repository by the author.

Items in Figshare are protected by copyright, with all rights reserved, unless otherwise indicated.

Nano-particle labelling of nucleic acids for enhanced detection by inductivelycoupled plasma mass spectrometry (ICP-MS)

PLEASE CITE THE PUBLISHED VERSION

PUBLISHER

(C) RSC Publishing

LICENCE

CC BY-NC-ND 4.0

REPOSITORY RECORD

Kerr, Samantha Louise, and Barry L. Sharp. 2019. "Nano-particle Labelling of Nucleic Acids for Enhanced Detection by Inductively-coupled Plasma Mass Spectrometry (ICP-MS)". figshare.

https://hdl.handle.net/2134/3124. 
This item was submitted to Loughborough's Institutional Repository by the author and is made available under the following Creative Commons Licence conditions.

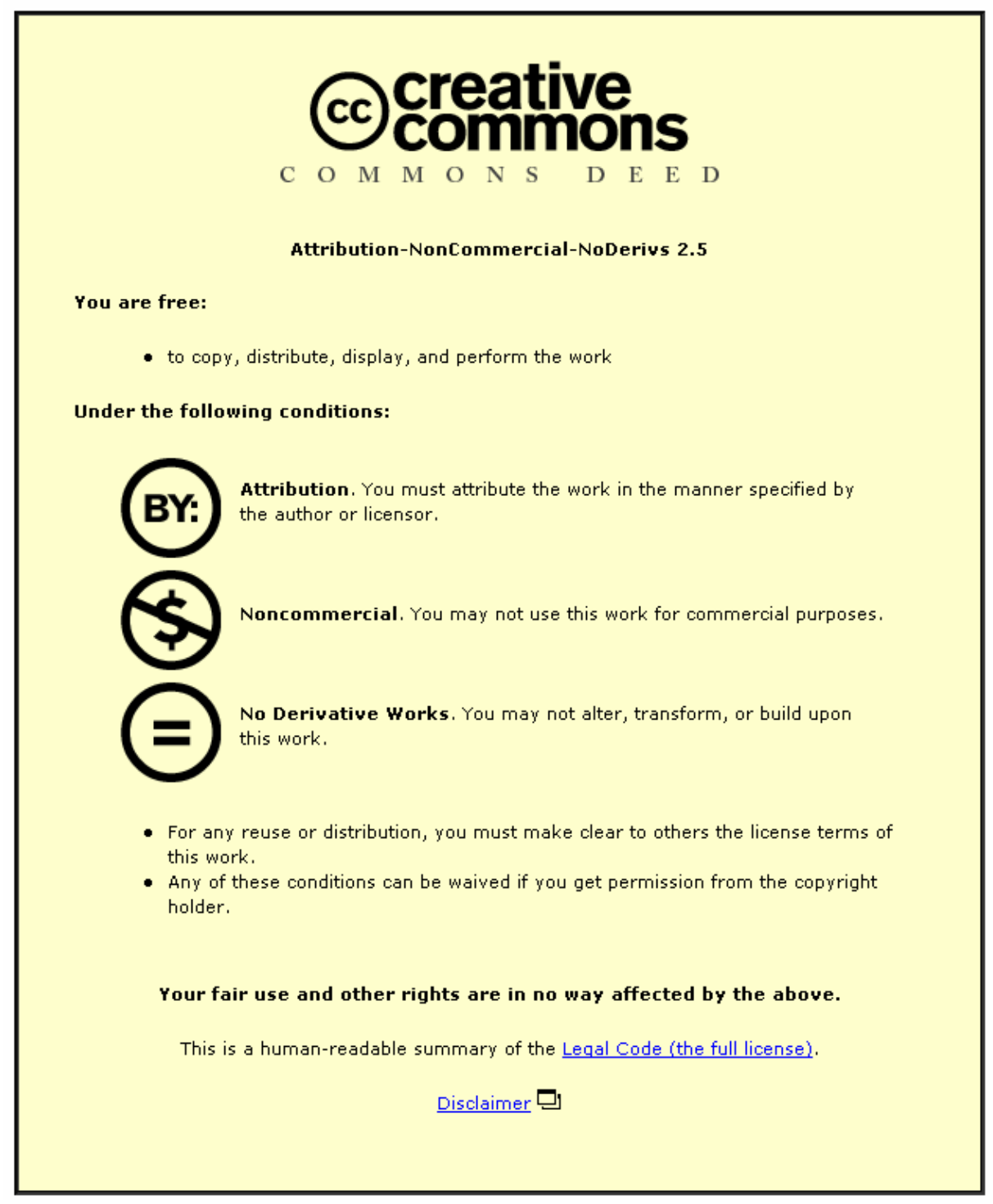

For the full text of this licence, please go to: http://creativecommons.org/licenses/by-nc-nd/2.5/ 


\title{
Nano-particle labelling of nucleic acids for enhanced detection by inductively-coupled plasma mass spectrometry (ICP-MS)
}

\author{
Samantha Louise Kerr and Barry Sharp* \\ Receipt/Acceptance Data [DO NOT ALTER/DELETE THIS TEXT] \\ Publication data [DO NOT ALTER/DELETE THIS TEXT] \\ DOI: 10.1039/b000000x [DO NOT ALTER/DELETE THIS TEXT]
}

\begin{abstract}
Oligonucleotides containing biotin functionality were successfully labelled with a streptavidin nanogold conjugate and subsequently separated and analysed by High Performance ${ }_{10}$ Liquid Chromatography-Inductively Coupled Plasma-Mass Spectrometry (HPLC-ICP-MS).
\end{abstract}

Inductively coupled plasma - mass spectrometry (ICP-MS) is the most sensitive and versatile analytical technique for providing elemental and isotopic information. Most elements in the periodic 15 table can be ionised in the ICP source including biologically important elements such as $\mathrm{P}$ and $\mathrm{S}$ and as a result, ICP-MS has been increasingly employed in the analysis of nucleic acids and proteins. ${ }^{1-3}$ ICP-MS provides complementary information to conventional organic MS and has many additional advantages. ${ }^{2,4,5}$

20 Firstly, ICP-MS offers very low limits of detection, which generally range from $\mathrm{pg} / \mathrm{l}-\mu \mathrm{g} / \mathrm{l}$ depending on the analyte. Calibration and quantification are much easier and require only inorganic elemental standard solutions. In addition, because ICPMS measures the total concentration of an element, regardless of 25 chemical form, it facilitates mass balance calculations, which are vital for establishing analyte recovery and method validation. Although the ICP is a hard ionisation source, molecular information can be obtained, for example by measuring P/S ratios in proteins, or by employing it as a selective detector coupled to 30 separation techniques.

Despite the advantages of ICP-MS, P and S are problematic elements because they have high first ionisation potentials $(10.5 \mathrm{eV}$ and $10.4 \mathrm{eV}$ respectively), which results in incomplete ionisation ( $35 \%$ and $15 \%$ for $\mathrm{P}$ and S respectively $)^{6}$, and they suffer from ${ }_{35}$ polyatomic interferences e.g. ${ }^{14} \mathrm{~N}^{16} \mathrm{O}{ }^{1} \mathrm{H},{ }^{16} \mathrm{O}_{2}$ and ${ }^{14} \mathrm{~N}^{18} \mathrm{O} .{ }^{7,8}$ Thus whilst metallic elements can readily be detected at pg/l levels, the detection limits for these elements are much higher. The collision reaction cell method converts the analytes $\mathrm{P}$ and $\mathrm{S}$ to their oxides at $\mathrm{m} / \mathrm{z} 47$ and 48 yielding detection limits of 1 and $1.5 \mu \mathrm{g} / \mathrm{l}$ for ${ }^{31} \mathrm{P}$ and ${ }_{40}{ }^{32} \mathrm{~S}$ respectively. ${ }^{9}$ For a sector instrument, running at 4000 resolution, the corresponding values are $50 \mathrm{ng} / \mathrm{l}$ for ${ }^{31} \mathrm{P}$ and $10 \mathrm{ng} / \mathrm{l}$ for ${ }^{32} \mathrm{~S} .{ }^{9}$ These problems can be avoided and the biomolecule signal enhanced if it is labelled with a metallic element or a metal nanoparticle which is measured instead of $\mathrm{P}$ or $\mathrm{S} .{ }^{10-11}$ The concept 45 of elemental labelling within the field of atomic spectrometry has been pioneered by Tanner et al. ${ }^{8,10}$, however, this area of research is still novel and continually developing.

Gold nanoparticles containing streptavidin functionality have been employed in this communication to label biotinylated DNA.

Department of Chemistry, Loughborough University, Loughborough, Leicestershire, LE11 3TU Fax: 01509 223925; Tel: +44 (0) 1509 222572; E-mail: b.l.sharp@lboro.ac.uk
50 Avidin proteins bind strongly to biotin with assosication constants in the region of $10^{15} \mathrm{M}^{-1}$, ${ }^{12}$ in what is known as the strongest noncovalent interaction. This property makes these two molecules ideal linkers for biomolecule labelling. The limits of detection for Au are much lower than those of $\mathrm{P}$ and $\mathrm{S}$ due to an absence of 55 interferences and a lower first ionisation potential. In addition, the biomolecule signal is further enhanced since each nanoparticle contains approximately 80 gold atoms. The ICP-MS analysis of $\mathrm{Au}$ labelled DNA has been reported elsewhere, ${ }^{13}$ however, the method employed DNA hybridised with a peptide sequence. Gold labelled 60 secondary antibodies were used to label a monoclonal antibody which was located at the peptide site on the hybrid biomolecule. ${ }^{13}$ The method detailed in this communication is site specific but not base sequence specific or dependent upon peptide sequences. It is therefore generic and can be applied to any nucleic acid that is 65 biotinylated. In addition, this method can be applied to small nucleic acids, such as dinucleotides which are produced in the post labelling assay, which are not suitable for PCR amplification. ${ }^{14}$

For quantitative analysis of the Au labelled oligonucleotides, it is essential to know how many gold atoms have been bound and 70 where. $^{11}$ To satisfy this criteria, site specific labelling is required, which was achieved by employing DNA biotinylated at the 5' end. Oligonucleotides containing 24 bases and biotinylated at the 5' end were obtained from Biotez (Berlin, Germany). The sequence of the oligonucleotides was as follows; 5' Biotin-TAT CTG TTC ACC 75 GCA AAT CTG TGG 3'. Alexa Fluor-488 FluoroNanogold Streptavidin (SFNG) was obtained from Nanoprobes (New York, USA). The attached gold nanoparticles are $1.4 \mathrm{~nm}$ in diameter and contain approximately $80 \mathrm{Au}$ atoms which are covalently attached to a streptavidin protein and Alexa Fluor-488 fluorophore. ${ }^{15}$ The 80 manufacturer states that there is an average of one nanogold particle to one streptavidin protein. Although streptavidin contains four biotin binding sites, only one or two of these sites may be accessible to the biotin in this case due to the steric restraints created by the presence of the nanogold and fluorophore. ${ }^{15}$

${ }_{85}$ The labelling of the biotinylated DNA was achieved by adding an excess of SFNG to the biotinylated DNA in a polypropylene vial. The reaction mixture was prepared by adding SFNG (1.33 $\mu \mathrm{M}, 83 \mu \mathrm{l})$ to the 5 ' biotinylated DNA solution $(2.24 \mu \mathrm{M}, 26 \mu \mathrm{l})$. Thus the reaction mixture contained: 58.7 pmoles biotinylated 90 DNA and 110 pmoles streptavidin which equated to 442 pmoles of biotin binding sites (assuming a total of 4 biotin binding sites per streptavidin molecule) and $17.12 \mathrm{mg} / \mathrm{l}$ gold. This reaction mixture therefore contained a potential 7.5 fold molar excess of biotin binding sites. The mixture was stored for approximately 48 hours at $954^{0} \mathrm{C}$.

Following the 48 hour reaction period, the reaction mixture was diluted so that the final solution contained $5.55 \mu \mathrm{g} / \mathrm{l}$ gold. This 
diluted sample was then injected onto a HPLC column in order to separate the bound and unbound SFNG (see Table 1).

100 A C18 column was chosen to provide a rapid separation based on size exclusion coupled with a small degree of hydrophobic interaction. A HP 1090 HPLC system (Agilent Technologies, Waldbronn, Germany) was employed; the column outlet was connected directly to the ICP nebuliser via a short length of 150 ${ }_{105} \mu \mathrm{M}$ internal diameter Teflon tubing. The eluent flow was split post column with a T-piece so that $\sim 300 \mu \mathrm{l} / \mathrm{min}$ of the mobile phase entered the nebuliser. The remainder of the mobile phase was sent to waste. An Element 2XR high resolution ICP-MS instrument (Thermo Finnigan, Bremen, Germany) was employed for the 110 determination of ${ }^{197} \mathrm{Au}$. The operating parameters are summarised in Table 1.

Table 1 Instrument Parameters

\begin{tabular}{ll} 
HPLC Parameters & \\
\hline Column & Waters C18 $\mu$ Bondapak 300 mm x 3.9 mm. \\
Mobile phase & $5 \%$ methanol in deionised water \\
Stop time & 5 minutes \\
Injection volume & $10 \mu \mathrm{l}$ \\
Flow rate & $1 \mathrm{ml} / \mathrm{min}$ \\
\hline ICP-MS Parameters & \\
\hline Analyte & ${ }^{197} \mathrm{Au}$ \\
Scan type & E-Scan 196.900-197.032 \\
Magnet rest mass & 196.966 \\
Cones & Pt sampler and skimmer \\
Nebuliser & PFA-LC (Elemental Scientific, Omaha, USA) \\
Spray Chamber & Cyclonic (Glass Expansions, Victoria, Australia) \\
\hline
\end{tabular}

A SFNG standard containing $3.66 \mu \mathrm{g} / \mathrm{l}$ Au was prepared from the stock SFNG solution. This standard solution was used for quantification and to establish the retention time of the unbound ${ }_{115}$ SFNG. Figure 1 shows the ${ }^{197} \mathrm{Au}$ chromatogram of the SFNG standard, which had a retention time of 1.57 minutes. The void volume of the column was determined with uracil, which had a retention time of 3.87 minutes. This indicates that the SFNG was totally excluded from the pore space in the column. A very small

120 peak was observed in the SFNG standard chromatogram at 1.06 minutes, which was attributed to carry over between samples. Gold has the disadvantage of being 'sticky' in nature and thus it can be difficult to completely remove all traces of the element between sample injections.

125 Figure 1 also shows the ${ }^{197}$ Au chromatogram of the DNA-SFNG reaction mixture which contains two peaks. The first peak at 1.06 minutes corresponds to the DNA-SFNG conjugate and the unbound SFNG eluted at 1.60 minutes, which is consistent with the retention time of the unbound SFNG standard in Figure 1. The DNA-SFNG 130 conjugate was the first species to elute because it is larger than the unbound SFNG and therefore, likely to be more excluded from the C18 phase. More importantly, the bound SFNG carried a highly charged oligonucleotide, resulting in less hydrophobic interaction with the surface of the non-polar stationary phase. The peaks were 135 integrated and the areas quantified using the SFNG standard. The Au concentration in the peaks at 1.06 minutes and 1.60 minutes was $2.97 \mu \mathrm{g} / \mathrm{l}$ and $3.11 \mu \mathrm{g} / \mathrm{l}$ respectively, thus total $\mathrm{Au}$ concentration was calculated to be $6.08 \mu \mathrm{g} / \mathrm{l}$ in the injected sample. However, the actual Au concentration in the injected sample was $1405.55 \mu \mathrm{g} / \mathrm{l}$, suggesting that $109.5 \%$ of the Au was recovered from the chromatographic phase. Errors in background correction were thought to be the reason behind the high recovery $(<100 \%)$, but this can be improved by improving the separation method. A control sample was also prepared which involved adding non145 biotinylated oligonucleotide to SFNG. The reaction conditions were similar to those described above. The control sample gave one peak with the retention time consistent with that of the unbound SFNG, as shown in Figure 1, thus implying that the reaction was site specific.

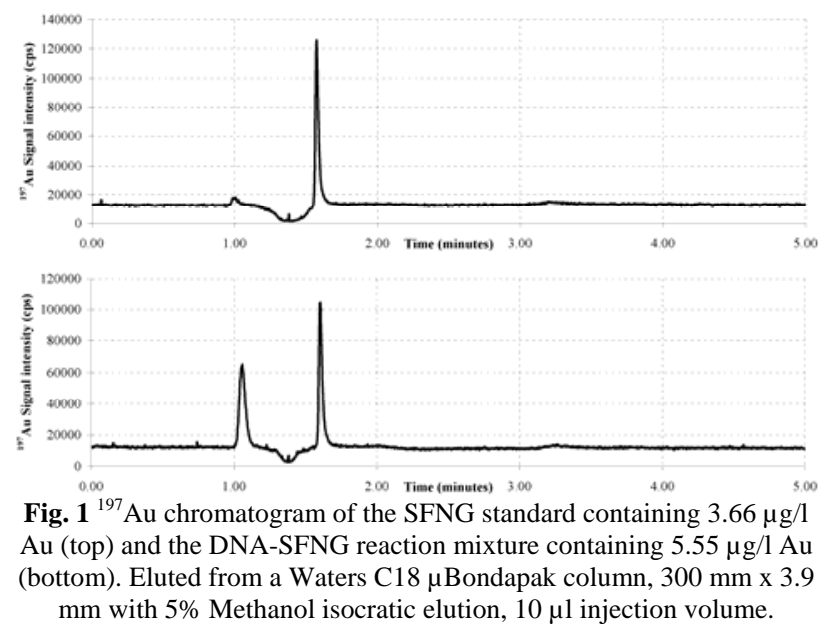

150 The SFNG was assayed to determine the number of $\mathrm{Au}$ atoms per nanogold particle. Two Au calibration curves were prepared, one for SFNG and one for an elemental Au standard. The slopes of the calibration curves were 4510624 ( $\mathrm{x}$ axis expressed as nM streptavidin) and 265217 (x axis expressed as $\mathrm{ng} / \mathrm{ml}$ ) for SFNG and 155 elemental gold respectively. From these data it was calculated that there were $86 \mathrm{Au}$ atoms per nanogold particle. This figure is slightly higher than that given by the manufacturer. However, the manufacturer states that there is an average of one nanogold particle to each streptavidin molecule, more than one nanogold ${ }_{160}$ particle per protein would increase the average number of $\mathrm{Au}$ atoms per particle and there may also be a small fraction of nanogold not bound to streptavidin. If either of these species were present they should be resolved from the DNA-SFNG conjugate during HPLC separation. No evidence of additional peaks was 165 observed in any of the chromatograms. The figure of $86 \mathrm{Au}$ atoms per nanogold particle was used for further calculations, although this assay was only applied to one batch of SFNG, it is unknown whether the figure varies between batches.

From the chromatogram, it can be concluded that $53.5 \%$ of the 170 nanogold and hence streptavidin was bound to DNA. Therefore, the number of moles of bound streptavidin in the reaction mixture was 58.9 pmoles. If one biotinylated DNA molecule bound to one streptavidin protein, then 58.9 pmoles of DNA also bound. Considering 58.7 pmoles of DNA was in the reaction mixture, $175100.3 \%$ of the DNA was labelled with SFNG. This data indicates that with a 7.5 molar excess of potential binding sites, or a 7.5/4 2 fold molar excess of nanogold probe, only one binding site per protein molecule was occupied. This is the optimum labelling stoichiometry since it equates to one $\mathrm{Au}$ nano-particle (86 $\mathrm{Au}$ 180 atoms) per oligonucleotide. If more than one oligonucleotide bound to SFNG, more than one conjugate peak would have been expected in the chromatogram since each additional oligonucleotide added to the SFNG would have resulted in an increase of $8 \mathrm{KDa}$ to the 
conjugate mass. As the separation appeared to have some size 185 exclusion character, such conjugates should have been resolved.

The Au background was consistent at approximately 12000 counts per second (cps), equivalent to $~ 70 \mathrm{ng} / \mathrm{l}$ of Au. This continuous flux of Au was thought to be hydrophobically bound SFNG from previous injections slowly eluting from the column. 190 Repeated injections of nanogold produced an accumulation of $\mathrm{Au}$ at the head of the column that could be reduced, but not totally removed by back flushing. The observed background Au signal may also have been enhanced due the presence of $5 \%$ methanol in the mobile phase which was shown to increase Au signals by $195 \sim 16 \%$. It has been suggested by Larsen et al., ${ }^{16}$ that the presence of carbon facilitates the ionisation of certain analytes in the plasma. ${ }^{16}$ This effect is well known for some elements with high ionisation potential such as Se and As. ${ }^{16}$ Rodushkin et al. ${ }^{17}$ have also reported that the addition of methane to the spray chamber increased the 200 signal intensity of some elements including Au. ${ }^{17}$ In addition, the presence of the organic solvent reduces the surface tension of the Au solution, which may improve nebulisation efficiency. ${ }^{16}$

The chromatograms shown in Figure 1 exhibit a dip in the baseline at approximately 1.4 minutes. This reduction in signal was 205 consistent and observed in all chromatograms, suggesting it was an injection related event. The mobile phase consisted of $5 \%$ methanol but the samples were diluted in deionised water. From the order of elution in Figure 1, it can be established that the DNA-SFNG conjugate eluted first followed by the sample solvent, which 210 contained a higher proportion of water compared to the mobile phase, and finally the unbound SFNG eluted. If the background $\mathrm{Au}$ was hydrophobically bound then the elution of the water solvent (a weaker eluent than methanol) would transiently reduce the Au flux from the column. Further, reduced carbon load and higher surface 215 tension of the water would reduce the Au signal further causing the temporary reduction in baseline signal.

The final aspect considered was the enhancement in signal due to SFNG labelling compared to that obtained by direct monitoring of ${ }^{31} \mathrm{P}$. To calculate the enhancement factor, two calibration curves 220 were prepared; one for ${ }^{197} \mathrm{Au}$ and one for ${ }^{31} \mathrm{P}$. The slopes of the calibration equations were 265765 and 1082 for ${ }^{197} \mathrm{Au}$ and ${ }^{31} \mathrm{P}$ respectively with the concentration axes expressed in $\mu \mathrm{g} / \mathrm{l}$. By comparing the gradients from the two sets of data, it was established that Au gave a 246 times greater response compared to

${ }_{225}$ P. The sensitivity of ICP-MS depends upon the number of similar isotopes in the sample, so the number of $\mathrm{P}$ and $\mathrm{Au}$ atoms also has to be considered. Each DNA-SFNG conjugate contained $24 \mathrm{P}$ atoms from the DNA phosphate backbone and $86 \mathrm{Au}$ atoms. Hence, each DNA-SFNG conjugate will have had 3.6 times more ${ }_{230} \mathrm{Au}$ atoms compared to P. Therefore, an 882 times increase in signal was observed for the Au labelled oligonucleotides. As indicated above, the detection limit for ${ }^{31} \mathrm{P}$ is typically $50 \mathrm{ng} / \mathrm{l}$, or given that $\mathrm{P}$ accounts for $\sim 10 \%$ by mass of DNA, $500 \mathrm{ng} / \mathrm{l}$ for DNA. The amplification achieved here lowers that to $\sim 500 \mathrm{pg} / \mathrm{l}$ or an ${ }_{235}$ estimated $5 \mathrm{fg}$ for a $10 \mu \mathrm{l}$ injection. The amplification factor improves for smaller nucleic acids, but deteriorates for larger nucleic acids in proportion to the number of $\mathrm{P}$ atoms.

The enhancement in signal requires that the nanogold particles are completely ionised in the plasma and thus behave as Au atoms.

240 Once the average number of Au atoms per nanogold particle was established, Au calibration curves for SFNG and elemental Au standards were compared. The gradients for the two sets of calibration data were 266226 and 265217 (x axis expressed as $\mu \mathrm{g} / \mathrm{l}$ in both cases) for SFNG and elemental Au respectively. The 245 calibration data confirmed that SFNG gave a similar response to the atomic Au solutions and is therefore ionised efficiently in the plasma. Recent work has suggested that for the plasma to process particles in a truly composition independent fashion requires them to be less than $90 \mathrm{~nm}$ in size (based upon the analysis of glass) ${ }^{18}$ 250 which is much greater than the $1.4 \mathrm{~nm}$ in diameter of the nanoparticles.

It has been demonstrated that nucleic acids can be labelled with $\mathrm{Au}$ nanoparticles and subsequently analysed by ICP-MS. Nanoparticle labelling coupled with elemental MS has several 255 advantages. The problems of polyatomic interferences that are encountered with ${ }^{31} \mathrm{P}$ detection are avoided. The bio-molecule signal is greatly enhanced by the higher sensitivity for ${ }^{197} \mathrm{Au}$ compared with ${ }^{31} \mathrm{P}$ and the presence of $\sim 86$ gold atoms per oligonucleotide. The data shown in this communication also 260 demonstrates that, unlike other techniques, ICP-MS can be utilised to establish mass balance for the nano-particle label thereby ensuring that all the labelled species from the reaction are both detected and quantified. A further benefit of the elemental analysis approach is that, post-separation, the stability of the molecular 265 species is not important since only the label is detected and at this stage quantification can be undertaken using simple acidic Au standards. ${ }^{8}$ The data presented here show that ICP-MS is an ideal complement to organic MS for the study of nucleic acids and offers enhanced detection and quantification.

\section{${ }_{270}$ References}

1 D. Pröfrock, P. Leonhard and A. Prange, J. Anal. At. Spectrom., 2003, 18, 708-713.

2 M. Wind and W. D. Lehmann, J. Anal. At. Spectrom., 2004, 19, 2025.

2753 W. Brüchert and J. Bettmer, J. Anal. At. Spectrom., 2006, 21, 12711276.

4 N. Jakubowski, R. Lobinski and L. Moens, J. Anal. At. Spectrom., 2004, 19, 1-4.

5 R. Lobinski, D. Schaumlöffel and J. Szpunar, Mass Spectrom. Rev., 2006, 25, 255-289.

6 D. Pröfrock, P. Leonhard, S. Wilbur and A. Prange, J. Anal. At. Spectrom., 2004, 19, 623-631.

7 D. R. Bandura, V. I. Baranov and S. D. Tanner, Anal. Chem., 2002, 74, $1497-1502$

2858 V. I. Baranov, Z. A. Quinn, D. R. Bandura and S. D. Tanner, J. Anal. At. Spectrom., 2002, 17, 1148-1152.

9 P. D. Winship, PhD. Doctoral thesis, Loughborough University, Department of Chemistry, 2006

10 V. I. Baranov, Z. A. Quinn, D. R. Bandura and S. D. Tanner, Anal. Chem., 2002, 74, 1629-1636.

11 J. Bettmer, N. Jakubowski and A. Prange, Anal. Bioanal. Chem., 2006, 386, 7-11.

12 E. Morag, E. A Bayer and M. Wilchek, Biochem. J. 1996, 316, 193199.

29513 A. Merkoci, M. Aldavert, G. Tarrasón, R. Eritja and S. Alegret, Anal. Chem., 2005, 77, 6500-6503.

14 C. W. Dieffenbach, T. M. J. Lowe and G. S. Dveksler, PCR Methods Applic., 1993, 3, 30-37.

15 Nanoprobes Incorporated, 20/06/07, http://www.nanoprobes.com

30016 E. H. Larson, J. Anal. At. Spectrom., 1994, 9, 1099-1105.

17 I. Rodushkin, P. Nordlund, E. Engström and D. C. Baxter, J. Anal. At. Spectrom., 2005, 20, 1250-1255.

18 H. R. Kuhn, M. Guillong and D. Günther, Anal. Bioanal. Chem., 2004, 378, 1069-1074. 